Open Access

\title{
Production of boundaries by social service organizations: based on the study of family integrated service centers in Guangzhou
}

Xiaoxing Huang ${ }^{1 *}$ (D) and Jie Yang ${ }^{2}$

\author{
* Correspondence: \\ huangxiaoxing@hotmail.com \\ ${ }^{1}$ School of Sociology and \\ Anthropology, Sun Yat-sen \\ University, 501-209A, No. 135, \\ Xingangxi Rd., Haizhu District, \\ Guangzhou, Guangdong, China \\ Full list of author information is \\ available at the end of the article
}

\begin{abstract}
Social service organizations have developed quickly as a result of the Chinese government outsourcing services in recent years. The policy of government outsourcing services has been successful in developed countries and is transferred to China mainland. However, there are critical differences between China and these areas. The precondition for success in outsourcing services in Western countries is that the nonprofit organizations are relatively independent and strong. In China, however, the relationship between the government and social organizations is fuzzy, and social organizations are still quite weak. Thus, the effectiveness of social service in the West depends on collaboration between the government and nonprofit organizations (NPOs), during which the boundaries are eliminated and partnership is built. The preexistent boundaries make sure that the government and NPOs could cooperate independently and equally. In China, boundaries should be produced first to assure the effectiveness of the government purchases of social services. This paper focuses on the family integrated service centers in Guangzhou and analyzes the production of boundaries in the process of service delivery strategies. It aims to respond to the partnership theory and theoretical issues regarding the development of social organizations in China.
\end{abstract}

Keywords: Social services purchased by the government, Social service organization, Boundary production, Partnership

Since 2008, the outsourcing of social services has become a common innovation governance strategy employed by the central government to improve the social management system. This has led to a change in the government's role in governance in major Chinese cities. The outsourcing of social services is a policy instrument that controls for social service supply and the development of partnerships throughout the governance network. The government is aiming to improve the effectiveness and efficiency of social service delivery. According to the Working Report of Civil Affairs of 2014 delivered by the Ministry of Civil Affairs of the People's Republic of China, the government spent nearly two billion yuan on social work service projects, and more than 3500 non-governmental social service organizations had been established for the purpose of supplying social service. ${ }^{1}$ While the total spent on purchasing social services continues to increase, the rapid development of social service organizations has caused many issues, such as the lack of specialization, the unclear relationship between social service

(c) 2016 The Author(s). Open Access This article is distributed under the terms of the Creative Commons Attribution 4.0 International License (http://creativecommons.org/licenses/by/4.0/), which permits unrestricted use, distribution, and reproduction in any medium, provided you give appropriate credit to the original author(s) and the source, provide a link to the Creative Commons license, and indicate if changes were made. 
organizations and others (the government, residents' committees ${ }^{2}$, etc.). These issues have led to complaints from both the government and social service organizations.

In December 2013, the author interviewed Mr. Yang, the director of BC sub-district administrative office in Guangzhou. Mr. Yang spoke about the operation of the Family Comprehensive Service Center in Guangzhou ${ }^{3}$ :

There are many problems (in the Family Integrated Service Center): whether the residents recognize this or not is not determined by the government that invests in public services. Even if you are enthusiastic and hope to do good deeds for everyone, you may receive complaints from them. There is no doubt that social work is a trend in social development; however, is it necessary to set up a special institution to supply services? The purchase of services is good too, for the increasingly complex division of labor in society. Now that social workers supply social services in a specialized manner, residents do not trust them, so it is hard to launch the project. And they are required to make achievements based on daily assessments, for the government invests so much money...I used to be in charge of civil affairs, in which I had to sort out the relationship between the family center and the residents' committee. I had to figure out what the relationship was, how to share resources, how to do the training, etc. We regularly summoned members of the residents' committee to communicate with social workers so that we can coordinate both groups. The Family Integrated Service Center ("FISC" in the following part) is still not clear about the situation in the street, yet 2 million has been wasted.

(Interview with Mr. Yang, director of the BC Sub-district, 13 Dec. 2013)

Obviously, as a purchaser, the director of BC sub-district administrative office was not satisfied with the effectiveness of the social service, not to mention the control of the process. The efficiency of public services is far away from satisfactory. But meanwhile, social service organizations have many complaints as well. The following is from the FISC interview with Mr. Wang, who is the director of FISC in the BC Sub-district, on May 23, 2014:

The boundary of FISC and the government is not clear. The government pays for the service, making resident services higher quality. This is the direction of social service reform. To determine how to best proceed will still require discussion and adaptation from both sides... (FISC) is kind of a public service unit (Shiye Danwei, 事业单位) without governmental orchestration (Bianzhi, 编制), so it is not a pure market economy behavior. FISC is not an independent individual, because it must cooperate with the sub-district government. At present, it cannot operate without the government on which it depends to grow. When these organizations mature, the government may let them operate on their own. When FISC enters, the government may negotiate and assign some complex tasks not limited to social work. So both parts need to adapt to each other so as to better understand their own role. The division between the residents' committee and me has gradually become clear. (Interview with Mr. Wang, director of FISC in BC Sub-district, May 23, 2014) 
This passage shows the dilemma the social service organization faces as it positions itself in the community: on the one hand, FISC is regarded as "a public service unit without governmental orchestration," but it tries to draw a boundary that separates it from the government; on the other hand, social service organizations in professional social work must uphold the social work ethic. However, there is strong tension between professional ethics as they have emerged in Western countries and the local Chinese culture. These two issues are common in China as social service organizations further develop. Social work, unlike in Western society, may not adapt to the local situation. The fundamental reason lies in the duality of deboundarification (means removal of boundaries) in Chinese context.

As Mr. Wang points out, social service organizations are "getting on the right track" and "breaking in" when entering into the community. He repeatedly mentions the importance of boundaries for the development of social service organizations. Social service organizations aim to benefit from the enabling of the government contracting-out service institutions. Such strategic activities of FISCs make the development of social service organizations quite different from the growth of social service organizations in Western countries.

In order to fully comprehend the development of social service organizations and social service supply, observations were conducted in different FISCs in Guangzhou; indepth interviews were also held with the directors and social workers of FISCs. From a social construction perspective, researchers and participants worked out the data through their interactions. The research questions are as follows: in the dual situation of deboundarification, how can social service organizations survive? How do social service organizations (including social service workers) produce boundaries? This topic is essential for the theories and policies for the social service organizations in China.

\section{Literature review and framework}

Organizational boundary is a longstanding research focus in institutional economics, institutional sociology, organizational sociology, and so on. "The boundary is where the discretion of the organization to control an activity is less that the discretion of another organization or individual to control that activity" (Pfeffer and Salancik 1978:32). The boundaries of social service organizations are embedded in different contexts of governance, and community social workers exist in a position between different social entities (Henderson et al. 2011). Boundaries are beneficial for organizational rationalization, and different strategies of organizational behavior arise in different boundary situations.

\section{Partnership and the disappearance of boundaries: social service boundaries in Western society}

Boundaries exist between the organization and the environment, and this is the foundation of organizational survival. "Boundary" describes the association between different organizations, which is inextricably associated with its deep-rooted traditions. As institutionalized, the organization is influenced by the social environment and history in which it grows (Zhou 2003). Social service organizations develop in unique ways, because they face different situations in different countries. Important situational variables include ecological variables, structure of public policies, and cross-sectoral relationships (DiMaggio and Anheier 1990). The relationship between the government and social service 
organizations is particularly important, for the relationship structure of them determines the social service models (Gidron et al. 1992; Najam 2000; Young 2000). Overall, the boundaries of social service organizations can be considered in three aspects.

Firstly, as a social subject, social service organizations require independence and autonomy. Social service organizations are a type of nonprofit organization (NPO). The development of NPOs in Western society represents the existence of independent civil society, which is separate from the state. This is essential for the protection of freedoms in Western society (Taylor 2005). Independent and opposing positions are reflected in the relationship between the government and the NPO according to the Dualism model. Both parts are in tension and conflict (Yu, 2005). NPOs are often constructed to be attached to or stand against the state (DiMaggio and Anheier 1990). The development of NPOs in Western society is based on the civil society of the West. This means that the organizational private space is outside of the formal boundary of a state (Salamon 2008:11-12). In public services, the political discourse employed emphasizes the root of conflicts between the public and private sectors and between private and state organizations (Salamon 2008:11).

Secondly, as a partnership, the relationships between different subjects in a community are considered as a type of resource acquisition, and different subjects are interdependent. Young (2000) noted that relationship between the government and social service organizations in different countries are unique. He summed up different strands of theories into three views that nonprofits (a) operate independently as supplemental support to the government, (b) work as complements as partners with the government, or (c) are engaged in an adversarial relationship of mutual accountability with the government (Young 2000). Different relationship types lead to different organizational strategies and results. In order to analyze the interaction between government and NPOs, Najam analyzes the relationship based on institutional interests and preferences for policy ends and means and then creates a four- $\mathrm{C}$ framework ("cooperation in the case of similar ends and similar means, confrontation in the case of dissimilar ends and dissimilar means, complementarity in the case of similar ends but dissimilar means, and co-optation in the case of dissimilar ends but similar means") (Najam 2000). Different patterns are based on the mutual power relationship between the government and NPOs, such as an authority pattern in summoning service funding and providing service (Gidron et al. 1992). The important dimension in differentiating a partnership is the relationship type between the organization and the funding source. Some scholars have summarized relationship types as follows: consultation of resource exchange, joint partnership, election, authority to acquire resources, and advocate for a marginalized group. These scholars argue that partnership is often preferred, yet it still depends on resource distribution and ways of achieving the target, etc. (Hardina et al. 2007:362). In the UK or the USA, the relationship between the state and civil society is changing from mutual independence to a cross-sectoral partnership, and boundaries between these different sectors may gradually disappear.

These two analytical approaches can be grouped under two names: "dualism" and "holism." The relationship between the state and civil society, in general, requires a switch from confrontation to cooperation (Yu, 2005). With the prevalence of the new managerialism and neo-liberalism, the government and NPOs cooperate crossing the boundaries in order to increase efficiency in both problem-solving and public resource 
usage. In this context, a new public management theory has emerged over time (Zhou and Dang 2013). But operation of this mechanism often requires cooperation between the government and social organizations, and this is only possible after eliminating the state-society boundary so as to promote cross-sectoral cooperation. The Western governments aim to reduce the transaction costs and promote the interdependence of organizations within the market by blurring boundaries (Kettle 2009:157). Some governments, as service purchasers, provide budgeted funds to the NPO that provides service. NPOs are best identified as "policy entrepreneurs" that influence policy-making and execution (Najam 2000). Yet the organizations also need to protect themselves from being controlled by their partners (Kettle 2009:157). At the present stage, the boundaries between the public, nonprofits, and for-profit enterprises are not clear.

Many scholars believe that governmental funding should be avoided, but Salamon thinks the funding exactly reflects the establishment of the partnership between the government and nonprofits. The national government creates an alliance network with many other sectors (Salamon 2008:53-54). Nonprofits may have many goals that they share in common with the government, so they may achieve cooperation rather than simply achieving interdependence. Under the condition of reform of liberalism, the partnership was destroyed and the nonprofits became increasingly commercialized. Salamon (2008:177) expressed his worries about this commercialization and expected that the partnership would be reconstructed. Salamon's theory of "third-party government" and partnerships is based on the research on the independence between the government and NPOs and on the research in which some scholars (such as Nisbet) criticize the deteriorating independence of NPOs and the government's role in leading and dominating in the public service domain (Nisbet 1953). Salamon reconstructs the pessimism of independence losing and regards the support of the government as a beneficial approach and an important mechanism of public service. Partnership supplements the relative separation of the state and society, bringing boundary issues into the public domain because of the need to clarify the rights and responsibilities of the government and social organizations. The basis of such partnership is the cooperation between the government and NPOs, both of which have clear rights and responsibilities. In this regard, responsibility sharing can be achieved so as to integrate resources and enhance the efficiency of public services.

Thirdly, as a profession, social work should maintain its professional position and remain distinct from other professions. Another boundary defines the system and the relationship among different systems, as determined by the professional role or work position. When professional service organizations have less autonomy, it will become increasingly difficult to manage the boundaries between the organization and the environment (Schneider 1987). The technical environment is the basis for professional service organizations. As examples, lawyers, doctors, and social workers in public services all work within their professional boundaries. From the perspective of professional function, the social function of the social work is "intersystem translation" (Abbott 1995). Social workers should manage the relationships among the community organizations, and the key role of them is working with others. No matter in the professionalization of social work or the social service provided by different sectors, boundary is a core concept.

The professional boundary of the social work draws on many perspectives of medicine (O'Leary et al. 2013). In the past, social workers were seen to be responsible for the 
boundaries between them and the clients, focusing on what the boundary is, rather than how it is created. As a result, the professional boundaries of social work become irrelevant with the theoretical and value development. O'Leary presents an alternative model of social work boundaries which emphasizes connection rather than separation and encourages a process of mutuality (O'Leary et al. 2013). In addition, Lavallée (2010) emphasizes the confrontation between the professional ethics of social work and local culture, and a point of blurring boundaries is raised. Boundaries of social service organizations are changing. While before they were clear, now they are becoming less boundaries and more cross-sectoral cooperation, which requires that the boundaries become more permeable. Social governance is based on the premise of a clear state-society boundary, which permits partnerships enabled through cross-sectoral cooperation between public and private sectors, in which the partnership can play its role better to solve the social problems.

\section{Boundary issues in the development of social organizations in China: analysis framework and theoretical response}

In developed Western countries, social service organizations are in the process of blurring boundaries with other sectors and reinforcing those collaborations. This trend sharply contrasts with that in China. Partnership theory does not explain the development of social organizations in China; neither can the existent social organization theory in Chinese academic literatures explain the current state.

First of all, the issues of organizational independence and capacity building are core ingredients in the partnership theory, but they are not existing in China mainland. The relationship between state and society in China is obscure. In China's history, the relationship between the "state" and "society" has been in a subtle equilibrium, that is, the boundary of both parts is not absolute, but related in essence (Yang 1998). There has never been a national civil society (Deng 2005). The long-term integration of government administration with commune management (zheng she he yi, 政社合一) made the state-society relationship unclear. "Regulations on the registration and administration of social organizations" in 1998 required that social organizations be supervised by a service master unit (ye wu zhu guan dan wei, 业务主管单位) and register in a registration authority (deng ji dan wei, 登记单位). This dual supervision led to the weak development of the social organization, unclear responsibilities and the messy development of the social organizations, etc. The system of differential controls of social organizations reflects the blending of the boundaries of the government and social organizations (Wang and Liu 2007). The development of social organizations is leading to a complex and diverse combination of "independence" and "autonomy," generalized as "dependent autonomy" (Wang and Song 2013). The premises of partnership theory (the independence and the growth of the nonprofit sectors) do not exist in China.

Secondly, social service organizations have few resources, leading to a one-way dependence on the government. In recent years, social organizations in China have undergone explosive growth because of the government procurement of services (Wang et al. 2014). Government funding is an important contributor to the development of social organizations. But the "state-society" relationship, in which the "society" is controlled by the "state," has not been changed, and the state takes entire control of the new economic environment in a "non-governmental" way (Kang and Han 2005). Salamon (2008) believes 
that government funding does not weaken the independence of the nonprofit sector because in the USA, private donations play an important role in sustaining nonprofits. However, in China, social organizations currently lack social resources because they have little public property (Wang and Liu 2007), and this leads to social service organizations having the one-way dependence on the government. Basically, social service organizations are restricted and cannot raise money from the society.

Thirdly, there is great tension between professional boundaries and Chinese culture. The former need to be clear, but the latter is obscure. Social service organizations face great pressure to professional, and this separates them from other organizations that can seek donations (Kuhn 2009). However, to establish clear professional boundaries for social service organizations, it is necessary to have an independent and individual citizenry and a willingness to engage in contracts, but the Chinese culture emphasizes human relationships (renqing, 人情), face (mianzi, 面子), “benevolence” (ren, 仁), "righteousness" (yi, 义), "politeness" (li, 礼), etc. (Shen 2007; Yan 2006; Zhai 2004), following its own rules. The professional ethics of social work requires social workers and social work agencies to maintain boundaries with clients, colleagues, and other institutions. Yet, in China, social workers often break these boundaries to provide professional services, which is an adaptation to Chinese culture.

Social service organizations in China are facing the dual context of deboundarification: one such context is rooted in state-society relations (institutional environment, social governance rules) and the other in the culture (technical environment, professional boundary) faced by social service. Both boundaries are constantly confined by different forces as a result of this tension. Social service organizations are embedded in community governance institutions and obscure boundaries among community organizations. They are restricted by government institutions, from bids on service supply, as well as the evaluation process. Nonetheless, social service organizations are required to maintain partnerships with the government and maintain clear responsibilities, while supplying services. In the process of contract outsourcing public services, information asymmetry between the government and social service organizations generates a space in which the rules by which social organizations define themselves and also can build a relationship with the government. This process is the first step in the process of deboundarification and boundary production. When providing social services, social service organizations are bound to come into conflict with the Chinese culture of "human ethics, human relationship and human destiny." Social work organizations and members often need to maintain intimate relationships with clients to provide social services, so the cultural sensitivity required from professionals is often relegated to the edge, and the trend of deboundarification is increasingly obvious. However, the professional ethics of social work requires social workers and social work organizations to maintain separate boundaries from clients, colleagues, other organizations, etc. This is the second step of deboundarification and boundary production. Social service organizations are facing with the dual context of deboundarification and production of boundaries, both of which occur and develop at the same time.

Due to different social situations, the theories of third-party governance and partnership represented by Salamon do not provide a suitable method for analyzing the purchase of public services by the Chinese government or the development of social organizations. The purchase of social services and government funding generates the interstitial space for the original obscure relationship, which facilitates boundary formation and change. 
Academia has not paid full attention to boundary issues nor has the function of intersystem translation been emphasized. The mainstream view on studies of social work in China is "embedded development" (Ge 2012; Wang 2011), including "political embeddness" or "system embeddness" (Xiong 2006). It is easy for this development to emphasize top-down control and to ignore the social service organization's independence, which requires the building of capacity and an emphasis on the value of service. Some scholars find that while entering the community context, social service organizations are easily absorbed by the power structure of the sub-district. Social organizations are absorbed into the mechanism of state administration and "social workers are becoming more administrative in external serving, more bureaucratic in internal control and more of institutionalization after being introduced into the power network of the community" (Zhu and Chen 2013). This reflects deviation from the essential requirements of NPOs and disappointment about the impossibility of keeping professional faith. When emphasizing social work development, regardless of its nature, social service organizations may be trapped as a service instrument (DiMaggio and Anheier 1990). The over-emphasis on the absorption and control of the subdistrict considers social service organizations as passive recipients and neglects their ability to initiate and spur further development. Moreover, both types of boundaries correspond to the issues of localization and professionalization. As a result, the academia may outweigh localization (the embedded development) or require additional professionalization (pessimism). Both stances have separate viewpoints, which are different or even opposite. They neglect the most important role of social service organizations in the balancing of boundaries: the interjacent role. Therefore, we need a more dynamic view of the development of the social service organizations. The paper focuses on the different stages and different parts of boundary production in the service supply process.

Based on the literature review, the article puts forward the following theoretical response and the analysis framework:

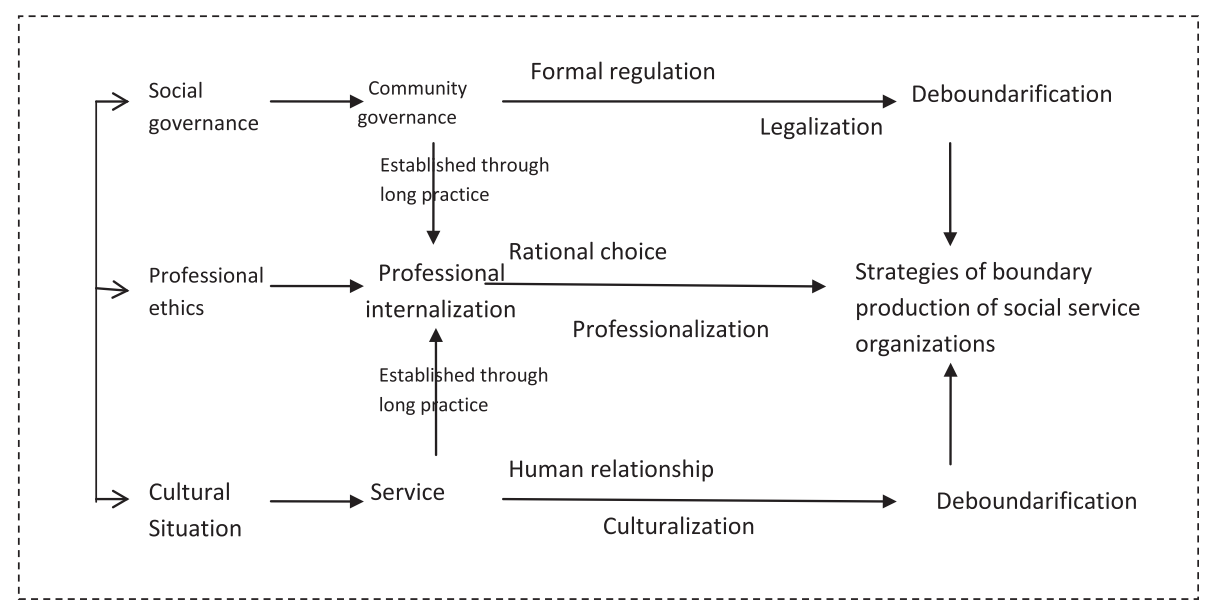

\section{Deboundarification and boundary production in the community governance context}

After the system of units (danwei, 单位) disintegrated, the state reshaped the community governance system, reconstructing its authority, so as to penetrate power into the residential block and even the daily life of the citizens (He 2006). Government regulations leave an imprint on the community governance system, and their boundaries are 
universally obscure. In the operation of resources and rules, social service organizations gradually have generated their own boundaries. The community governance system is the first social environment the social service organizations face.

\section{The positioning of social service organizations in the governance context: self-positioning and the interaction}

Community governance is the process in which multi-level subjects participate in community public affairs (Xia 2012; Zhang 2010). In the implementation of community construction, Chinese urban community is a governance unit constructed from top to bottom (Yang 2007a). The government constructs a platform for community governance at the community level; meanwhile, social service organizations also require resource integration and platform construction.

In 2008, Guangzhou municipal government began to purchase social services for particular groups from social service organizations, such as "Youth Zone." In 2009, it began to follow the Hong Kong mode, in which a full range of services was provided for residents, with the "Community Comprehensive Service center" (the former FISC) as the carrier, and with a budget of two million yuan per year, although some subdistricts had more than two million, which was distributed by the municipal and district finance departments in varying proportions. The initial purpose of the "Community Comprehensive Service Center" was to reform the system of both public affairs and public institutions. Every FISC is equipped with 20 working personnel, 15 being social workers or related professional personnel, and 5 being other personnel. ${ }^{4}$ FISC, as the permanent social service carrier of the sub-district, is a component of the "one team, three centers" in Guangzhou. The author interviewed directors or secretaries of the party committee in different sub-districts and found that the major criteria that they used to evaluate FISC were whether it could share responsibilities with the office of the sub-district and effectively serve the residents. In describing the project, Mr. Yang repeatedly compares FISC with the residents' committee:

The residents' committee is a reasonable solution in China because it meets the needs of the present Chinese situation. If we need to provide comprehensive family services, it will change the status of the residents' committee...Social work is a trend of social development, but whether we need to establish an organization that specializes in this, including purchasing the service, is an issue. The division of the society is more and more delicate, yet for the current governance system of the country, we need to put talent into residents' committees. This is more influential than merely establishing FISC. The resources can be integrated to achieve an advantage. (interview with Mr. Yang, director of BC Sub-district, 13 Dec, 2013)

FISC services overlap in part with those from the residents' committee. Therefore, the sub-district office, as a service purchaser, wants to absorb FISC into its own power structure. However, the social service organizations aiming to take over FISCs are outsiders. In some sub-districts, such cooperation is smooth, while in others, conflicts occur. During the interview, the deputy director of the GD residents' committee in BC sub-district showed complaints and criticism of FISC both through language and gestures. He thought that FISC did not cooperate well with the sub-district or with the 
residents' committee and it only implemented a series of programs designed by itself without considering the actual effect of community service; FISC has intermediate effect, but the personnel are paid more than those in the residents' committee (interview with HG, deputy director of the residents committee in GD community, BC Subdistrict, 18 Dec. 2013). FISC is often confined to finish the tasks required in the contract, and the scope of services is limited to a small range of people. Usually, FISC requires the residents' committees to provide information, but it does not cooperate with the residents' committees to carry out the work (interview with Mr. Song, director in ZN residents committee, NST sub-district, 16 Feb. 2015).

The complaints from the sub-district offices and residents' committees reflect the situation directly faced by FISC. The power structure of the sub-district is stronger, and it can decide whether FISC is in or out. For example, in 2012, the pilot FISC was replaced in the BC Sub-district. Regardless of professional issues, one important cause was the bad relationship between FISC and the sub-district office. The funding of the government's purchase of social services exerts great influence on the mode of community governance and development (Geoghegan and Powell 2006).

Facing the dilemma above, FISC has different positioning strategies:

1. Direct embedding strategy. Social service organizations directly cooperate with offices in the sub-district with which they have a close relationship and ignore the boundaries. This strategy is commonly used in most social service organizations when entering into the sub-districts in Guangzhou. The pilot FISC in Guangzhou took two modes: Mode 1: the government purchased services directly from social service organizations; Mode 2: the sub-district office founded a private non-enterprise organization to undertake the purchase of social services (Huang and Xu 2011), a step generally determined by sub-district requirements without concern for the cooperation from the residents' committee.

Following Mode 1, some social service organizations taking over FISCs are founded by government-affiliated institutions (such as Supply and Marketing Cooperatives), which maintain intimate relationships with the sub-district office. As an example, BF Social Work Service Center ("BF Center" in the following part) is the social work organization founded by the supply and marketing cooperative. It has taken over many FISCs in Guangzhou. Mr. Li, the general director of BF Center, thinks that the need for FISC originated with the switch of function in the sub-district as a component of the power structure. He does not approve of the concept of social service organizations as civil organizations. FISC belongs to the sub-district, so it must assist the sub-district and the government deal with relevant issues. The so-called division of partnership and assistantship is based on the ability of FISC. "If you can succeed at full capacity, then you are a partner; if you put yourself as an assistant (huo ji, 伙计) accepting everything that you are asked to do, then you are an assistant." (interview with Mr. Li from BF, 10 Dec. 2014). The assistants immediately obey employer arrangement; yet time is required to build up and maintain a partnership. Therefore, social service organizations must enhance their ability to seek certain positions in the community governance system. The best chance to seek legalization of the organization from the government is the purchase of social work services. 
2. Contingency strategy. FISC is a stable component of the governance system of the sub-district in Guangzhou, but the social service organizations that take over FISCs are not stable. They are responsible for assigning social workers. Such instability leads to an unstable choice of strategies for social service organizations. A contingency strategy is required in this situation. Social service organizations adjust based on requirements from the purchaser of FISC as well as the depth of the social services required at different stages. This approach is one of comparative positioning.

Many social service organizations divide the first period (3 years) into different stages, which have different positioning strategies depending on relationships between groups. The FISC in the sub-district of LRDF has different goals for each year (interview with director Huang, FISC at LRDF, Jun 4, 2014). In the first year, the center focused on publicity to expand the service so as to build a good relationship with the sub-district and residents committees; in the second year, the number of professional service and cases began to rise; in the third year came the initial effect, and projects were being processes, such as the creation of a community canteen for the elderly that was needed because of the comparative age of the residents, a "community ambassador" activity, a family volunteer project, etc. Such positioning will be determined in interaction with the leaders in the sub-district office.

3. Professional maintenance strategy. Social service organizations emphasize their professional position based on boundaries of skill and knowledge to seek selfregulation and management (Geoghegan and Powell 2006), and this is the basis of social work and its source of professional authority. FISC in SY Sub-district was undertaken by CQ organization, which was founded by a professor in a famous university. When Ms. Huang, the FISC director, talked about positioning, she emphasized the professionalism of social work services, yet this insistence was regarded by the sub-district office as "stupid and down-to-earth" (interview with Ms. Huang, director of FISC in SY Sub-district, 22 Apr. 2014). She highlights the partnership with the residents' committees, emphasizing the division between and cooperation with each according to her ability. However, the over-insistence of the social service organizations on the professional strategies and maintenance of comparatively clear boundaries may lead to the organization being replaced. There had been such a case: a FISC in one district in Guangzhou ranked no. 1 or no. 2 in the evaluation, but it was eventually replaced because of the bad relationship with the sub-district office (interview with Mr. Lin, director of FISC in NY Sub-district, 23 Apr. 2014).

The strategies above are not the only choices or mutually exclusive. Different FISCs adopt mixed strategies to position themselves, and they have different relationships with sub-district offices or residents' committees. After entering into the community governance system, social service organizations hope that through their own efforts, they can construct or influence the relationship with the sub-district offices and residents' committees. For example, Mr. Li, the director of FISC in HT Sub-district, regards the leader in the sub-district as a client who expects to change the sub-district office. 
Overall, the three organizations have built up a permanent communication system and they influence each other through continuous interaction.

\section{The uncertain boundaries between the organizations: mutual dissolution and change of boundaries}

With the growth of social service organizations and the deepening reform of the country's political system, social service organizations form their discourses in the process of managing their boundaries with the government. In different stages, the boundaries are uncertain and in different states.

1. Obscure boundaries exist during the bidding stage as services are being contracted out

FISC in HX Sub-district was undertaken by BF center in September 2012. BF center was founded in 2009. It initially undertook FISC in ZJ Sub-district, and their work there was observed by some national leaders and became well-known. Because of its reputation, HX Sub-district officers selected BF center to be the social service supplier. $\mathrm{BF}$ center was an expansion of the supply and marketing cooperative, where the director of HX had previously worked. He invited BF center to undertake the FISC of HX sub-district. In this way, BF center strengthened their relationship (guanxi, 关系) and resources. Before beginning work in HX sub-district, BF center completed extensive community analysis and assessment research with cooperation from the sub-district office and residents' committees. The function of connections played a pivotal role in facilitating the organization to be on the right track.

It is important for the sub-district office to choose social service organizations by cooperating with the intended organizations to complete a demand assessment of the residents in the sub-district in advance. This is because the assessment and program design usually determine whether the social service organization would be successful in the contract competition or not. HX sub-district office played an important role in helping $\mathrm{BF}$ center win the bidding of the contracting-out service contract.

\section{Selective mobilization for resources in the process of service delivery}

Resources integration is one important service provided by social service organizations, but resource dependence can lead to an obscure relationship between the social service organizations and other organizations. Therefore, some FISCs adopt a selective mobilization strategy for resources and make sure they can use the resources independently.

"PA Social Services Center" ("PA" in the following part) has a background similar to that of BF. PA relied on a strong network to succeed in bidding for FISC in the $\mathrm{BC}$ Sub-district. GD community, in which IFSC of BC Sub-district is located, is a star community for the government. ${ }^{6}$ A number of enterprises have formed long-term cooperation with the GD residents' committee, and they are willing to invest substantial human and material resources to support community services here. After entering the GD Community, PA was a free rider that absorbed resources without selection.

In the first year, we were a bit silly. That is to say, I don't know whether other FISCs have a similar advantage. But in this community, because of its fame, many 
enterprises are willing to cooperate with the community, and we just accepted it. We provided what you asked. (interview with Mr. Wang, director of BC Sub-district, 23 May, 2014)

Mr. Wang considered this as silly because when there are resources, there is cooperation. Service is provided as long as there is need. FISC gradually adopted the operation mode of residents' committee for building up a strong relationship as well as acquiring more resources for service providing. Yet this method makes FISC basically fully inherit the operation method of the sub-district office and residents' committee, but FISC deviates from the original positioning of the organization and its professional mission. As the professional value and self-value are lower compared to numerous service activities, members of the FISC were upset.

It is hard for us to operate because when the resources flock in, we are all driven by them. We lost tempo. And then there would be a deviation in the direction because we were resource-driven, not driven by the goal of our center. (interview with $\mathrm{Mr}$.

Wang, director of BC Sub-district, 23, May, 2014)

The following year, BC FISC fully adopted new thinking by creating separate projects to rationally use the external resources, that is, "to drive the resources." The project "Table of Love" encouraged enterprise personnel to care for the elderly in the community. A stable volunteer team was formed afterwards. Based on the concept and mode of "Community Care," all resources were gathered on the Table of Love, which distinguished itself from others by its own concept and service, thus strengthening its professional legitimacy.

Thus, in the process of resource integration, FISC in BC Sub-district aimed to switch its position to a professional one and tried to shape clear professional boundaries. Social service organizations may eliminate boundaries with the government to acquire resources for survival, namely, institutional support and financial assistance. There may be a lot of incompatibility when professional social work is embedded in the local power structure, such as the perception of not being professional. However, the boundaries of different organizations in community differ according to changes in time and space. Such boundaries will also develop, mature, and adjust for social service organizations.

\section{Selective cooperation of sub-district services}

FISC in Guangzhou proceeded according to a " $3+2$ " approach. ${ }^{7}$ The author constructed the following list by searching for the "lowest service working hour" in the most-recently released bids on the website "Guangzhou Community Service" (Table 1). Two projects from each district were chosen:

Of the 22 projects above, the one requiring the smallest number of service working hours required 14,184 per year, with the highest requiring 38,200, and the average requiring 26,689.5. Nonetheless, the documents from Guangzhou government require that there should be 15 professional social workers among FISC personnel. Therefore, the working hours for each person per day (based on 365 days per year, including weekends and holidays) are $4.87 \mathrm{~h}$, which is only calculated as service working hours 
Table 1 The "lowest service working hours" and bid organizations in FISC projects in Guangzhou (website:http://gzsg.gzmz.gov.cn/)

\begin{tabular}{|c|c|c|c|}
\hline & Bidding projects (sub-district) & District & Minimum working hours per year (unit/hour) \\
\hline 1 & L1 & $\mathrm{L}$ district & 30,131 \\
\hline 2 & L2 & $\mathrm{L}$ district & 25,100 \\
\hline 3 & Y1 & Y district & 30,184 \\
\hline 4 & Y2 & Y district & 28,098 \\
\hline 5 & Z1 & Z district & 25,416 \\
\hline 6 & Z2 & Z district & 24,429 \\
\hline 7 & G1 & G district & 26,568 \\
\hline 8 & G2 & G district & 23,602 \\
\hline 9 & B1 & B district & $20,183.75$ \\
\hline 10 & B2 & B district & 23,454 \\
\hline 11 & $\mathrm{~T} 1$ & T district & 33,997 \\
\hline 12 & $\mathrm{~T} 2$ & $\mathrm{~T}$ district & 29,500 \\
\hline 13 & $\mathrm{H} 1$ & $\mathrm{H}$ district & 38,200 \\
\hline 14 & $\mathrm{H} 2$ & $\mathrm{H}$ district & 30,800 \\
\hline 15 & P1 & $\mathrm{P}$ district & 21,904 \\
\hline 16 & P2 & P district & 28,156 \\
\hline 17 & S1 & S district & 25,112 \\
\hline 18 & S2 & S district & 27,008 \\
\hline 19 & $\mathrm{C} 1$ & C district & 29,556 \\
\hline 20 & $C 2$ & C district & 29,064 \\
\hline 21 & N1 & $\mathrm{N}$ district & 22,540 \\
\hline 22 & N2 & $\mathrm{N}$ district & 14,184 \\
\hline
\end{tabular}

without adding time for training, supervision, or external exchange. Ms. Zhu Jingjun ${ }^{8}$ thinks the most appropriate number of working hours for FISC is between 20,000 and 21,000; therefore, it is unreasonable for the bidding proposal to expect working hours of more than 30,000. Based on the contract, it is hard to fulfill professional tasks, not to the extra administrative tasks required by the sub-district office. ${ }^{9}$ As a result, some FISCs choose to finish the tasks required in the contract, which can "protect" them from some other affairs.

When the organization is embedded in the power structure of the sub-district, the boundaries suffer actual or potential impact from the external environment because, in essence, the organization is an open system relying on the exchange and dialog of energy and resources with other systems. The service purchased by the government creates a buffer between the people and the government, and such a buffer is exactly the space for the social service organizations. As the owner (and provider) of social service techniques, social service organizations operate within the buffer. Moreover, the division of boundaries is determined according to the two aspects: one is the social boundaries between the social service organizations and the sub-district offices, the residents' committees, the enterprises or public institutions, or other social organizations; the other is the professional symbolic boundaries of social work undertaken or constructed by social service organizations. Both boundaries determine the size of the buffer. It is impossible for the government or social organizations to maintain their own 
boundaries, which are not "separate from each other," but can be mutually dissolved. When time and space change, boundaries will also change.

\section{Deboundarification and the production of professional boundaries in the cultural context}

Social service organizations are required to establish boundaries in the governance system, as well as to confirm these boundaries with the clients. The division of boundaries means the promotion of the professionalization process, which is another basis by which the social service organizations survive. Managers of such organizations are required to maintain continuous interaction with different groups from internal and external environments (Hardina et al. 2007:10). In addition, to clarify service boundaries and client boundaries, it is necessary to focus on the appearance of the professional role.

\section{Cultural sensitivity and boundary flexibility: relationship with clients}

The word "boundaries" appears nine times in the Code of Ethics of the National Association of Social Workers in the USA, such as professional ability boundaries, dual relationship or multiple relationships in conflict of interest, and the avoidance of sexual relationship. Social workers have the responsibility to maintain client boundaries, and they should maintain clear and appropriate boundaries that match the sensitivity of the local culture (Dolgoff et al. 2005). However, when professional social work confronts the traditional culture in China, social workers could promote service activities based on the refined private relationship with the clients. Such private relationships are established by breaking through the boundaries of professional relationships with clients.

In February 2012, FISC in QN Sub-district officially conducted service activities. As the organization that undertook the FISC had no inside relationship with the government, it was hard to conduct the community assessment. However, due to the full use of youth groups as a community resource, FISC was established as the center for youth games and activities, and as a result, more community residents became involved in the FISC service. Further, strong trust and support to the social workers developed. Nonetheless, Ms. Liang, a social worker, found that at first, the teenagers mainly communicated with her regarding problems of conducting the games and activities, but later, the problems were related to personal emotions. Many teenagers became couples, and some teenagers sent private messages to her in the Wechat group. Actually, the social worker noticed this and told the supervisor, who then provided obscure guidance: to take appropriate control to balance professionalism and the personal relationship. But here is a dilemma: due to the physical and psychological characteristics of adolescent groups, if social workers want to ensure the smooth development of the service process, they have to "repeatedly" get teenagers involved. Through the process, they hope to appeal to the adolescents as friends, rather than from their role as professional social workers. Once social workers fall into a friendship, it is difficult for them to interact without concrete guidance from the Code of Ethics for Social Work in China. From the perspective of professional social work in Western society, social workers in China are often trapped in ethical dilemmas. 
The interruption of values and boundaries of service: establishment of a professional role In the values and ethics of social work, social service organizations serve marginalized groups and help them speak for themselves. The important values of social work are service, social justice, etc. ${ }^{10}$ Social workers should represent vulnerable groups. All the above requires that social workers mediate between different social subjects to acquire resources for clients. If the issues originate from the society as a result of resource distribution, social service organizations should express the needs of marginalized groups (Hardina et al. 2007:361).

HX FISC once raised more than 30,000 yuan for a child with acute leukemia as well as subsidies for serious diseases, gathering support by selling hand-made silk flowers and other gifts. In an interview with Mr. Wang, the director of BC FISC, he emphasizes the responses to social issues from the social service organizations. The most impressive example he remembered was the support for a family in the community. The companion role of being a social worker for the clients was emphasized. There were four people in the family, including the couple, a 70-year-old grandma, and a daughter in kindergarten. The husband, the sole breadwinner, passed away suddenly, and the wife was helpless. Social workers first introduced grief counseling and discussed with the wife on their living to help them overcome the hardship. In this process, the social service organization played a role in resource coordination and direct services by assisting the wife in having her husband cremated, in responding to grief and providing support as she started her new life (including job recommendation, linking resources), and so on. The significance of social workers is to speak for those marginalized individuals or groups and to link resources, and this has become the mission for most social service organizations and the meaning of social work.

Social service organizations need to cooperate with different organizations, and they understand the professional significance of maintaining their own ethics. In Chinese culture, the privacy of different people or groups tends to be overlooked (Yang 2007b). In the social welfare policy (such as the minimum living assurance system, home assurance system), the means test of the family, monitoring income changes, neighborhood supervision, etc. were required, so privacy was not considered or emphasized. In an interview with the secretary of BC Sub-district, she mentioned the last organization (it was replaced) that was responsible for FISC in BC, and this organization was unwilling to report to the sub-district office about clients' situations. She expressed her disappointment. Most clients of social service organizations are low-income families. So social workers must obey and insist on social workers' professional responsibilities and ethics of secrecy. The director in HL Sub-district thinks the cooperation is based on a win-win situation, yet social workers insist on following their own ethical stance. In other words, if the work requires that they go against social work ethics, cooperation will end.

Obviously, in service provision, social service organizations emphasize ethical issues in particular, and professional ethics become an important symbol of the boundaries that separate social workers from others. A key way to analyze professional groups is to analyze self-regulation of professional issues. In order to maintain the professional social identity, professional personnel aim to construct mutual values, regulations, ethics, etc. (Lawton 2008:129). When the cultural context is unclear, social service organizations attempt to establish two-level boundaries: the first is to construct social 
boundaries with clients so as to be cultural sensitive and to speak for marginalized groups; the second is to establish symbolic boundaries with other professionals under the framework of professional ethics, to highlight the nature of social work, and to emphasize professional self-regulation.

\section{Service supervision, assessment, and boundary adaptation}

The UK and other countries initiated the privatization of local public services through contract outsourcing. But due to the poor quality of services, it is important to establish a monitoring system. The government generally hopes to monitor the activities and performance of the private sector through performance index monitoring (Kirschen 2009:162-179). In FISC, service supervision includes daily monitoring and assessment (process assessment, mid-term assessment, and final assessment). In the process of service supervision and assessment, different governments, as service purchasers, adopt a number of ways to manage and control social service organizations; third-party assessment organizations develop and use assessment techniques in order to enhance their professional authority. The continuous confrontation between social service organizations and third-party assessment organizations generates boundary disputes.

Sub-district supervision and management and the involution of social service organizations

In actual operation, there are adjustments from the initial pilot to the comprehensive expansion of FISCs. In "Note for printing 'Three Working Principles during the Testing Construction of Community Comprehensive service center in Guangzhou'" (Bureau of Civil Affairs of Guangzhou, document no. 320 in 2010), party A (sponsor) was the district (county city) government or its working department; party B was (respondent for project execution and management) sub-district office; and party $\mathrm{C}$ was the organization undertaking the community comprehensive service center in the subdistrict. In the document from Communist Guangzhou Municipal Office, "Communist Guangzhou Municipal Office, Guangzhou Government Office printing: the Note 'About the execution of accelerating the construction of family integrated service center"' (Guangzhou government office, Document No. 22, 2011), the bureau of civil affairs in district (county city), the corresponding sub-district, and the bid organization arranged to sign the FISC contract. The bureau of civil affairs in the district (county city) is the supervisor for the execution of the contract, the office of sub-district is the purchaser purchasing social services, and the bidding social service organization is the service provider. We can see that the administrative power of the sub-district office has greatly increased, from the execution and management of projects, to the purchaser. "The Execution Approach for Assessment of Purchasing Social Service of Guangzhou Municipal Government" and "The Process Regulation for Service Purchase of Government Executed by Community Comprehensive Service center in Sub-district in Guangzhou" specify that the responsibilities of the sub-district office include requirement assessment, calculation of service cost, planning of total amount of service, and setting of service projects. In addition, as for the FISC service plan, service outcomes, fund management, and so on will directly affect its survival and development. Under such regulations, each FISC establishes regular communication mechanisms by which they communicate with the sub-district office via regular meetings. The FISCs in HL and TD Sub-districts 
must report to the sub-district offices with written documents including working data and service content. The sub-district office has a joint meeting system, involving the FISC director and the project leaders; these individuals report on and negotiate in developing annual and quarterly plans. Through joint meetings, the FISC director enables the leader of the sub-district to learn more about the service of social workers. Meanwhile, the sub-district offices express their demands through regular meetings to ask for cooperation from FISC. For example, social workers are involved in the activity of building up a happy community, publicizing the risks of dengue fever, and so on.

The result of planning and consultation is a general plan for the social service organizations to cooperate with the sub-district, rather than following professional requirements or even the original contract. The sub-district can also judge the comprehensive capacity of the social service organizations through the daily activities of FISC. The term of the contract is 3 years, and the contract is signed once a year. If the organization successfully passes the final assessment every year, the contract will continue; otherwise, the sub-district office will choose a new operating organization again. In an interview with Ms. Huang, the director of FISC, (in CQ Sub-district, 22 Apr. 2014), she said that the sub-district office has the full power in deciding service supplier. Whether social service organizations can continue to supply services is determined by the sub-district office. In that sense, there is no change between the governmental controls in terms of the actual operation of social organizations. Government control of resources and speech make the involution more serious for social organizations, and social forces allow for no real change or growth.

Some assessment organizations ${ }^{11}$ highlight the relationship between the social service organizations and the sub-district offices. The assessment contains "Central Coordination System," which emphasizes coordination with the government (including residents' committees). It is impossible to separate social service organizations from the government. If the relationship is handled properly, the government will protect the organization because it is in its own interests; otherwise, the organization faces the risk of replacement at any moment.

The assessment organization sets up the interview with the purchaser, with the interviewee typically being the deputy director of the sub-district, the civil affairs department leader, or other civil servants specializing in FISC. The interview consists of the following parts: communication between the FISC and the purchaser, goodness of fit, and satisfaction between the FISC and project index, whether the FISC meets the community requirement, changes, and recommendations for the community. Such assessment is used by the sub-district office to determine satisfaction regarding comprehensive family services, which generally directly affects the overall assessment score for the FISC.

In 2014, the author participated in the mid-term assessment for the FISC in NXG. Mr. Chen, the leader of the civil affairs department in the sub-district, expressed his idea for the FISC. He thought that due to the constant turnover in the FISC director position, communication between the FISC and the sub-district had not improved. Further, the FISC did not cooperate with the sub-district office or the residents' committees. Personally, he positioned the FISC as a "supplement to governmental work" to provide services not covered by the government. Overall, the FISC had failed to fulfill its corresponding tasks, not to mention to respond to the requirements of the community. Although he continued to emphasize that the problem in the FISC was normal for 
all the newly born, the recommendation of the assessment was still to complete an assessment in advance. This was because the assessment affected the bidding during the next term, and the sub-district was thinking about handover issues. Judging from his tone, the sub-district office was not satisfied with this social service organization. In 2015, after the expiration of the 3-year contract, the original organization undertaking the FISC in NXG was replaced by another.

Emphasizing purchaser attitudes could avoid situations in which a high score is obtained but without meeting purchaser requirements. ${ }^{12}$ The sub-district office looks forward to absorbing FISC into the power structure; when there is deviation, it would put the social service organization "on the right track" through various strategies. The supervision makes the boundaries maintained by the social service organizations shrink. To make matters worse, some social service organizations even have become administrative organizations and lost the professionalism required of social work.

\section{Professional regulation and adaptation of social organizations}

Sub-district regulations and professional regulations may be in tension or directly conflict with each other. Professional regulations aim to enhance the professional capacity of social service organizations and provide more professional services. On the one hand, NPOs must present the responsibilities and altruistic motives to the society, and this requires alliances with other organizations; on the other hand, NPOs must shoulder greater "professional pressure" as acknowledged by society, national institutions, and potential donors. In addition, they must generate meaningful innovation and development performance, yet professionalization requires that NPOs separate themselves from other organizations (Kuhn 2009). The government sets a certain number of goals for professional tasks to regulate social service organizations. But as a delegate, the government finds it difficult to complete professional regulation, which is undertaken by third-party assessment drawing from experts.

Professional assessment consists of three parts: interviews with social workers, reference documents, and project logic. Experts firstly listen to the director or the social workers as they report on service progress from the last assessment, including completion indicators, content in different areas, and adjustments based on the last assessment. Then according to the report, experts comment and communicate with FISC employees. Four to five experts take turns in asking questions and exploring the professionalism of service development. In the session, experts tend to ask questions and discuss the demands, planning, objectives, effectiveness, and other aspects. Social service organizations are required to meet the needs of the clients and communities.

After discussion, assessment experts are divided into three groups for further interviews. Each group requires cooperation from social workers. First of all, the expert responsible for the interview session holds a discussion with selected staff in the field of interest. The choice may be made at random, but it tends to be a field recommended by the FISC. The fields include services for teenagers and families. The interviews cover the center's mission, administrative system, professional system, satisfaction in supervision and training, internal communication system, external communication system, goals and job content in their own field, the degree of agreement with the community, and so on. Generally, the assessment expert starts from the particular service area to 
discuss service progress so as to evaluate the understanding and effect of service from the social workers' perspectives. The mission and prospects are related to the topic of the values of social work, which is the essence of social work organizations. To some extent, it strengthens the acknowledgement of its values. Moreover, each interview aims to remind social workers to cultivate these values. Therefore, the assessment tends to be steering-style education. The authoritative experts, from time to time, communicate with social workers to remind them to be aware of the various values and professional issues.

Reference documents allow assessment of a measurable index and service effects. Experts review cases, as well as documentation of groups and community events. Then, they choose some documents at random for detailed reading and check for completion by referring to the index. Social workers are present during the whole process and organizations are supposed to answer questions from assessment experts. When different theories are used in cases, some experts even ask the social workers to explain the process and its limitations, so as to judge how deep the social workers understand the theories and to assess the credibility of the documents.

The last part is project logic, mainly used to verify the logic of project design for the FISC as a whole, including service planning and the activity plan, whether such plans meet the needs of the entity and whether there is an integral idea, etc.

Staff in each center are required to cooperate in the whole process of each assessment, so the center is not open when the assessment occurs. As for different parts of the assessment, social workers need to prepare a lot of written documents, which leads to a burden for some social workers who have the nickname "Written workers." The professional assessment controls the development direction of the FISC through interviews, documents, and project logic to stay on a professional track. When experts are confronted by the director or the FISC staff, sometimes, the debate is fierce because the FISC fails to reflect the professionalism required by experts. Yet the FISC may argue that the expert comment hardly fits the situation for the organization or the community. After the debate, the expert comment will always be included as a report with a score with recommendations about how the FISC can improve. Such procedure, to some extent, pushes each FISC towards the professional boundary and avoids overinvolution. Organizational boundaries and professional boundaries intertwine to make the FISC wander, reposition itself, and adjust.

\section{Conclusion and discussion}

Although influenced by institutions of community governance and professionalism of social work, the development of social service organizations in China has different boundary production conditions. Two kinds of boundaries are confined by different forces, such as cultural pressure in service supply and dual pressures from the purchaser and the assessor under supervision. In this dual context, the development of social service organizations presents a different context than that in Western society. The premise of partnership theory is not applicable for China, and the theoretical conclusions of embedded development and the absorption of sub-district power structure can only reflect part of its development.

Choosing social work organizations as a research object, this article finds two contexts for deboundarification: firstly, deboundarification occurs between the government 
and social service organizations; secondly, deboundarification occurs in the progress of service supplying in the local cultural context. In such situations, social service organizations aim to generate their own social boundaries and symbolic boundaries, which range from obscure in the bidding process to clear in the process of providing service, and the maintenance of relationships among different entities in the service progress, as well as the confirmation and insistence on the professional role.

The government has actively promoted the reconstruction of social relationships (Jia 2005:248). Although the government's purchase of social services drives the opening of boundaries in the public domain, social service organizations still depend too strongly on the government. Community governance is the first situation that social service organizations face. The original boundaries are obscure without cross-boundary cooperative partnerships, and it is hard to generate such partnerships. At different stages of social service delivery, social service organizations consciously operate at their boundaries to gain recognition. They hope to build boundaries with the sub-district power structure, but the latter is eager to absorb the former. From the bidding process, social service organizations are involved into the sub-district power system; thus, they need to depend on the fixed power of the sub-district office and residents' committees to ensure consolidation. The boundaries are universally obscure. However, once service is carried out, social service organizations gradually determine their position through the operation of resources and rules. They gradually acquire the capacity to collaborate equally with different subjects (especially the residents' committee), from a one-way dependent relationship towards two-way cooperation. In this process, the residents' committees also need to rely on the social service organizations to complete service and even assessments. As for social service organizations, they need to constantly keep and consolidate their status and function in the sub-district to not only receive more resources but also to clarify the boundaries among different organizations.

The relationship between social workers and clients has also been targeted because of its importance to the direction of boundary studies. Social structures that combine politics and society have long been deeply affected by the "home" culture, and the concept of "the Pattern of Difference Sequence" (Fei 1988) is quite useful in explaining the relationship. However, the boundary is not clear. Social work that exists in different cultures must face the social situation of great difference in China. So by blindly duplicating the code of ethics found in Western professional social work and the practice system that it follows inevitably makes it difficult for local social work to make progress. Such a focus may even ignore the dynamic function, the action logic, and survival strategies of local social service organizations.

In the dual contexts of deboundarification, social service organizations need to constantly test, explore, and attempt to generate different boundaries, and this is different from our Western counterparts. So far, Guangzhou has completed the first cycle of 3 years in the purchase of services, and at least three development directions can be observed: firstly, directly exit or not enter. When boundaries are obscure or professional service is not available, some organizations choose to quit or not to enter into this area. If professionalism is overly emphasized, it is possible to fail to achieve cooperation. Secondly, intermediate compromise (semi-professional). With a cooperative attitude, the organization can set aside the separation of partnership and assistantship but focus instead on ability improvement so as to acquire the best position in the sub- 
district power structure. Thirdly, deprofessionalization and maintaining a distance through professionalism. Such organizations fully comply with the instructions of subdistrict offices and do not care about the boundaries, and they may emphasize the local community characteristics and the cultural sensitivity of ethics, but neglecting professional skill and expertise.

Therefore, the third-party government-partnership theory cannot explain the development of social service organizations in China; neither can it be explained by the theoretical perspective of embedded development of social service organizations. The premise of the third-party government theory is the existence of a relatively independent relationship between the state and society and the strong development of NPOs. Based on this premise, cross-boundary cooperation brought about by the government may lead to more efficient public service. When the theory is used to explain the development of social service organizations in China, it is similar to direct adoption. The point of the embedded development of social work, as emphasized by Chinese scholars, has a comparatively strong functional structure, regardless of the dynamics of the development process or of social organization strategies. From the stand of society, the view that social service organizations are absorbed may only reflect one pattern of boundary production. However, determining how to reposition the boundary role of social service organizations is of great importance.

Social service organizations, as part of the community, have as a core function the interjacent coordination so as to operate among different boundaries in different organizations. Balancing various boundaries becomes core to the mission of community social work (Henderson et al. 2011). The process of community work in the past has been "worker-centered," that is, the effect of the interaction between workers and residents depends on the worker's personality, skills, and other characteristics. To improve the community action, the "worker-centered" is supposed to be changed to "we-centered" to highlight the collective side of community work, which overlays the boundaries of groups, organizations, and professions. Community work tends to cross boundaries in order to promote societal change (Henderson et al. 2011). As it is related to politics outside of the social work profession, the behavior of other voluntary entities and the redefinition of social work, the issue of boundaries between social organizations (community organizations) and the environment is critical (Reisch and Wenocur 1986). According to utilitarianism, social work is a profession of interstitality. According to ecological theory, social work is a complex defended turf in the system of professions. In the network-constitutive approach, social work arises out of a set of social "boundary groups" capable of assembly into such a defensible turf (Abbott 1995). Therefore, social service organizations should not be separate from the community but should emphasize the role of balancing different organizations (between bureaucracy and the primary groups in community) (Litwak and Meyer 1966). The production of professional boundaries, in essence, is the control and operation of the boundaries of different organizations. The production of the second level should be based on the first. When studying social service organizations, the tension of their place should be emphasized and their role in boundary change should be revealed. Understanding how to operate the boundaries is also important. The tensions between these boundaries usually arise from the relationship between administration and culture, and they are determined by the natural role of social service organizations. Only if social service 
organizations are placed in the interjacent position can the current development of social work, the community organization and governance, be analyzed from a more systematic and accepting sociological perspective.

\section{Endnotes}

${ }^{1}$ Website: http://www.mca.gov.cn/

${ }^{2}$ The residents' committee (居委会, Juweihui) is a legal authorized self-government organization in the urban community in China mainland.

${ }^{3}$ In the testing phase, the Family Integrated Service Center was called the Community Comprehensive Service Center, and the development of the center was an important step forward for Guangzhou, both as a way to promote reform and to support innovation in service management, both for the community and for the sub-district. Please refer to "The note for printing 'Pilot Program for Advancing the Reform of Community Management Services in Guangzhou to Carry out Community Service Centre Testing Construction"' (Bureau of Civil Affairs of Guangzhou, document No. 213 in 2010), "Note for printing 'Three Working Principles during the Testing Construction of Community Comprehensive Service Center in Guangzhou"' (Bureau of Civil Affairs of Guangzhou, document No. 320 in 2010), the document from the Guangzhou Committee of the central government, "Comment on the reform and innovation of the management for sub-district and community services focused by Guangzhou Committee of the central government and the People's government in Guangzhou" (Guangzhou government, document No. 14 in 2011, 23 July, 2011), the document from the Communist Guangzhou Municipal Office, "Communist Guangzhou Municipal Office, Guangzhou Government Office printing "The Note 'About the execution of accelerating the construction of Family Comprehensive Service Center" (Guangzhou government office, Document No. 22, 2011), which reads, "family Comprehensive Service Center refers to a service platform for a sub-district, guided by the department of civil affairs for the district or county city. Family Comprehensive Service Centers are operated by the service organization for civil social work through the purchase of social services from the government. It is based on the actual need of area service, with the core of family, youth, and the elderly to set up service projects and to provide professional, comprehensive and fine social service to all community residents." In the present phase, there are 171 family Comprehensive Service Centers, with most sub-districts having one center and others having two centers. The service budget is normally two million a year, with 2.5 million a year in Luogang District."

4"Regarding how the construction of the Family Comprehensive Service Center was executed at an accelerated pace" (Guangzhou government office, Document No. 22, 2011).

5"One team, three centers" refers to the comprehensive law enforcement team that includes a service center for the political affairs in the sub-district, the center of comprehensive governance and stability maintenance and FISC.

${ }^{6} \mathrm{GD}$ Community is a community governance model that BC Sub-district focuses on. As a star community, it receives many visits.

7 "3" refers to "the young, the old and family service"; " 2 " refers to "special projects in sub-districts and communities."

${ }^{8}$ Website: http://dhzw.gzzx.gov.cn/cf123/yxta/201401/t20140124_33071.html 
${ }^{9}$ When the Guangdong provincial government purchases service, social work organizations are required to meet proposal requirements, such as working hours of individual clients, or group and community activities. Then, they also need to maintain a good relationship with other organizations, especially those with the government. Therefore, when social work organizations hold professional service activities, they should cooperate with governmental organizations in the sub-district, which exert an essential influence on the continued existence of such organizations. For example, the "Central coordination system," based on the relationship with governmental organizations, occupies a large valuation in the assessment.

${ }^{10}$ Website: http://www.socialworkers.org/pubs/code/code.asp

${ }^{11}$ There are different third-party assessment organizations in Guangzhou, but in the first period, different districts had different assessment criteria. The assessment here is for one of the two districts in Guangzhou that the author participated in, and the assessment index may differ in other districts. For example, only professionalism may be assessed in some districts. In the second period, the assessment criteria will be uniform in Guangzhou. The recent "Note for the bid in the assessment of family Comprehensive Service Center and service for supervision arrangement" stated that there are four sub-groups in the FISC. The Social Work Association in Guangzhou is responsible for assessment training supervision and mid-term assessment of FISCs in Guangzhou. The Social Work Expert Association in Guangdong and The Assessment and Development Center of Welfare Service in Guangzhou are responsible for the final assessment for district A and district B, respectively. Dongshan Suidong Tax Office Co., Ltd. in Guangzhou is responsible for the financial assessment.

${ }^{12}$ After the pilot FISC in 2012, some assessments resulted in high scores, but the corresponding organizations failed to undertake the FISC, which drew negative public opinion.

Competing interests

The authors declare that they have no competing interests.

Authors' contributions

$\mathrm{XH}$ conceived the study, participated in its design, and drafted the manuscript. JY performed the data analysis and helped to draft the manuscript. Both authors read and approved the final manuscript.

\section{Acknowledgements}

This paper is funded by the National Social Science Fund (CN) (15CSH076), The Ministry of education of Humanities and Social Science project (CN) (13YJC63005), and National Social Science Fund (CN) (15ZDA046). The authors would like to express their gratitude to Xu Yongxiang, Zhu Jiangang, Wang Xing, Zhang Xiang, Wang Shuixiong, Tan Haibo, Tang Yuanxiong, Liu Xiaochun, Tu Jiong, Wang Jun, and Xu Yingyan.

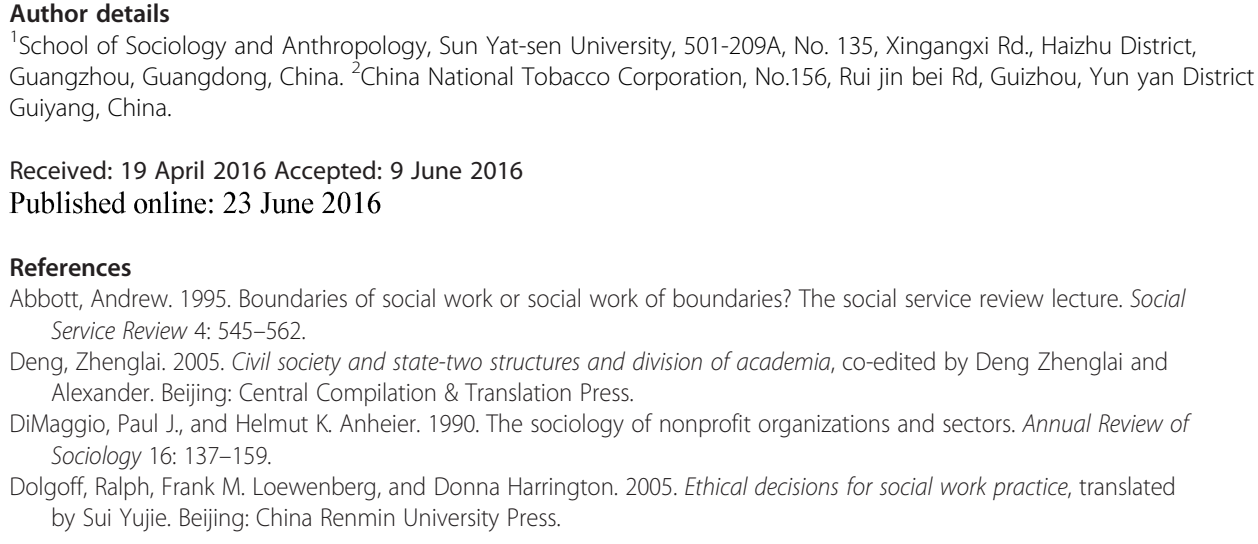

${ }^{1}$ School of Sociology and Anthropology, Sun Yat-sen University, 501-209A, No. 135, Xingangxi Rd., Haizhu District, Guangzhou, Guangdong, China. ${ }^{2}$ China National Tobacco Corporation, No.156, Rui jin bei Rd, Guizhou, Yun yan District Guiyang, China.

Received: 19 April 2016 Accepted: 9 June 2016

Published online: 23 June 2016

References

Abbott, Andrew. 1995. Boundaries of social work or social work of boundaries? The social service review lecture. Social Service Review 4: 545-562.

Deng, Zhenglai. 2005. Civil society and state-two structures and division of academia, co-edited by Deng Zhenglai and Alexander. Beijing: Central Compilation \& Translation Press.

DiMaggio, Paul J., and Helmut K. Anheier. 1990. The sociology of nonprofit organizations and sectors. Annual Review of Sociology 16: 137-159.

Dolgoff, Ralph, Frank M. Loewenberg, and Donna Harrington. 2005. Ethical decisions for social work practice, translated by Sui Yujie. Beijing: China Renmin University Press. 
Fei, Xiaotong. 1988. The pattern of difference sequence. In The anthology of Fei Xiaotong, ed. Fei Xiaotong. Tianjin: Tianjin People's Publishing House.

Ge, Daoshun. 2012. The construction of social work system: the content, setting and embedding. Study and Practice 10: 81-89.

Geoghegan, Martin, and Fred Powell. 2006. Community development, partnership governance and dilemmas of professionalization: profiling and assessing the case of Ireland. The British Journal of Social Work 5: 845-861.

Gidron, Benjamin, Ralph M. Kramer, and Lester M. Salamon. 1992. Government and the third sector in comparative perspective: allies or adversaries. In Government and the third sector : emerging relationships in welfare states, ed. Gidron Benjamin, Ralph M. Kramer, and Lester M. Salamon. San Francisco: Jossey-Bass Publishers.

Hardina, Donna, Jane Middleton, Salvador Montana, and Roger A. Simpson. 2007. An empowering approach to managing social service organizations. New York: Springer Publishing Company.

He, Yanling. 2006. The political rights and reconstruction of authority for the grassroots in city in the community construction activity. Social Science in Guangdong 1: 159-164.

Henderson, Paul, David Jones, and David Thomas. 2011. The boundaries of change in community work. In The Community Development Reader: History, Themes and Issues, ed. Gary Craig, Marjorie Mayo, Keith Popple, Mae Shaw, and Marilyn Taylor. Bristol: The Policy Press.

Huang, Xiaoxing, and Yingyan Xu. 2011. The models of community social work through government contracting-out: status, problems and countermeasures. The Greater Pearl River Delta Forum 3: 45-56.

Jia, Xijin. 2005. The third reform: strategic analysis of non-profit departments in China. Beijing: Qinghua University Press.

Kang, Xiaoguang, and Heng Han. 2005. The system of differential controls: a study of the state-society relationship in contemporary China. Sociological Studies 6: 73-89.

Kettle, Donald F. 2009. Sharing power- public governance and private markets, translated by Sun Yingchun. Beijing: Peking University Press.

Kirschen, Harry. 2009. Provide the service for places/cities. In Providing Public Service, translated by Meng Hua, ed. Anwar Shaw. Beijing: Tsinghua University Press.

Kuhn, Berthold. 2009. Development policy between markets and state: possibility and limitation of organizations in civil society, translated by Sui Xueli. Beijing: China Renmin University Press. Chinese translation.

Lavallée, Lynn F. 2010. Blurring the boundaries: social work's role in indigenous spirituality. Canadian Social Work Review 1: $143-146$.

Lawton, Allen. 2008. Ethical management for the public services, translated by Feng Zhouzhuo, tang Lindi. Beijing: Tsinghua University Press.

Litwak, Eugene, and Henry J. Meyer. 1966. A balance theory of coordination between bureaucratic organizations and community primary groups. Administrative Science Quarterly 1: 31-58.

Najam, Adil. 2000. The four C's of government third sector-government relations. Nonprofit Management and Leadership 4: 375-396.

Nisbet, Robert A. 1953. The quest for community: a study in the ethics of order and freedom. New York: Oxford University Press.

O'Leary, Patrick, Ming-Sum Tsui, and Gillian Ruch. 2013. The boundaries of the social work relationship revisited: towards a connected, inclusive and dynamic conceptualisation. The British Journal of Social Work 1: 135-153.

Pfeffer, Jeffrey, and Gerald R. Salancik. 1978. The external control of organizations: a resource dependence perspective. New York: Harper and Row.

Reisch, Michael, and Stanley Wenocur. 1986. The future of community organization in social work: social activism and the politics of profession building. Social Service Review 1: 70-93.

Salamon, Lester M. 2008. Partners in public service: government-nonprofit relations in the modern welfare state, translated by Tian Kai. Beijing: The Commercial Press.

Schneider, Susan C. 1987. Managing boundaries in organizations. Political Psychology 3: 379-393.

Shen, Yi. 2007. The daily practice of "benevolence", "righteousness" and "courtesy": "relationship", "favor" and "face" - the actual position of the Confucianism's "great tradition" in the daily "small tradition" from the perspective of "the pattern of difference sequence. Open Times 4: 88-104.

Taylor, Charles. 2005. Modes of civil society. In The State and Civil Society-a Research Approach of Social Theory, ed. Deng Zhenglai and Alexander. Beijing: Central Compilation \& Translation Press.

Wang, Ming, and Qiushi Liu. 2007. Analysis on institutions for NGO development in China. The China Nonprofit Review 1: $92-145$.

Wang, Ming, et al. 2014. Social organizations and social governance. Beijing: Social Sciences Academic Press (China).

Wang, Shizong, and Chengcheng Song. 2013. Independence or autonomy: the reflection of the issues of the characters in China's social organizations. Social Science in China 5: 50-66.

Wang, Sibin. 2011. The embedded development of social work in China. Social Sciences Front 2: 206-222.

Xia, Jianzhong. 2012. The study on the community governance structure in urban China. Beijing: China Renmin University Press.

Xiong, Yuegen. 2006. The practical logic and system embedding in localization development process in social work in China. In Professionalization and Localization Practice in Social Work, ed. Sibin Wang. Beijing: Social Sciences Academic Press (China).

Yan, Yunxiang. 2006. The hierarchy of the pattern of difference sequence and Chinese culture. Sociological Studies 4: 201-213.

Yang, Lin Qiwen. 2007a. Why do social workers value confidential principles. In Insisting the Belief-30 Letters for Students Majoring in Social Work, ed. Gan Bingguang, Chen Weidao, and Wen Jinyan. Hong Kong: Hong Kong City University Press.

Yang, Min. 2007b. Community as state governance unit—a case study on residents' community participation and cognition in the process of community building campaign. Sociological Studies 4: 137-164.

Yang, Nianqun. 1998. "Civil society" in the historical study in modern China. In Nation and Society, ed. Zhang Jing Hangzhou: Zhejiang People's Publishing House. 
Young, Dennis R. 2000. Alternative models of government-nonprofit sector relations: theoretical and international perspectives. Nonprofit and Voluntary Sector Quarterly 1: 149-172.

Yu, Weihua, 2005, On the Relationship between NGOs and Government - From the Perspective of Resource-interdependence Theory, Journal of Public Management, Vol. 2: 32-39.

Zhai, Xuewei. 2004. The favor, face and reproduction of power-the social exchange modes in reasonable society. Sociological Studies 5: 48-57.

Zhang, Zhaoshu. 2010. Urban issues and social multiple agents' joint governance-the analysis of three types of urban governance organizations in Hangzhou. Management World 2: 46-59.

Zhou, Xiaoli, and Xiuyun Dang. 2013. Western social governance: mechanism, ideas and enlightenment. Social Science in Nanjing 10: 75-81.

Zhou, Xueguang. 2003. Ten lectures on the sociology of organizations. Beijing: Social Sciences Academic Press (China).

Zhu, Jiangang, and Anna Chen. 2013. The embeddedness of professional social work into the power relations of urban community: a case study of government service purchase. Sociological Studies 1: 43-64.

\section{Submit your manuscript to a SpringerOpen ${ }^{\circ}$ journal and benefit from:}

- Convenient online submission

- Rigorous peer review

- Immediate publication on acceptance

- Open access: articles freely available online

- High visibility within the field

- Retaining the copyright to your article

Submit your next manuscript at $\boldsymbol{~ s p r i n g e r o p e n . c o m ~}$ 